\title{
Antibacterial effect of silver diamine fluoride and potassium iodide against $E$. faecalis, $A$. naeslundii and P. micra
}

\author{
Benjamín Briseño-Marroquín ${ }^{1,2}$, Yasmine Ismael ${ }^{2}$, Angelika Callaway ${ }^{2}$, Christian Tennert $^{1}$ and \\ Thomas Gerhard Wolf ${ }^{1,2^{*}}$
}

\begin{abstract}
Background: The aim of this study was to determine in vitro the bactericidal potential of $38 \%$ silver diamine fluoride (SDF) alone, potassium iodide (PI) alone, and the two in combination (SDF + PI) against three bacterial species commonly found in root canal samples (Enterococcus faecalis, Actinomyces naes/undii and Parvimonas micra).

Methods: The potential bactericidal rates for SDF, PI and SDF + PI against E. faecalis, A. naes/undii and P. micra were calculated as reduction of bacteria colony forming units.

Results: The bactericidal potential of SDF was at $99.97-100 \%$ against $E$. faecalis and $100 \%$ against $A$. naes/undii and $P$. micra. SDF + PI showed a 100\% bactericidal effect against P. micra, 99.89-99.98\% against E. faecalis and 99.98-100\% against $A$. naes/undii. The bactericidal effect of PI was 99.51-99.98\% against E. faecalis, 99.27-99.95\% against $A$. naeslundii and $99.93-100 \%$ against P. micra. The differences between controls and bacteria exposed to the antibacterial agents were statistically significant $(p<0.05)$.

Conclusions: SDF had an effective bactericidal effect against the examined bacteria. However, the limitations of this in vitro study do not allow a recommendation of the employment of these solutions as root canal irrigants. Additional investigations are necessary to assess their endodontic clinical applicability.
\end{abstract}

Keywords: Bactericidal effect, A. naes/undii, E. faecalis, P. micra, Potassium iodide, Silver diamine fluoride

\section{Background}

Various types of injuries are the cause of pulp inflammation, which can ultimately lead to irreversible pulpitis and consequently through contamination to pulp necrosis [1]. Entry paths for microorganisms into the tooth pulp system are mainly caries, periodontal disease [1] or trauma [2]. Dahlén [3] reported that bacteria such as lactobacilli, streptococci, actinomyces and Gram-negative

*Correspondence: thomas.wolf@zmk.unibe.ch

${ }^{1}$ Department of Restorative, Preventive and Pediatric Dentistry, School

of Dental Medicine, University of Bern, Freiburgstrasse 7, 3010 Bern,

Switzerland

Full list of author information is available at the end of the article obligate anaerobes are often the cause of this type of inflammation.

The removal of inflamed and/or necrotic pulp tissue, and thus, of established bacteria is the main purpose of the mechanical and chemical shaping and cleaning process of the root canal system. Mechanical preparation of the root canal ensures shaping of the root canal; yet, a complete removal of infected and/or non-infected material cannot be accomplished. For almost a century the chemical cleaning of the root canal system has been recommended [4]. The standard solution for this purpose is sodium hypochlorite, which is recommended in concentrations from 0.5 to $5.25 \%$ [5], being the only root canal bactericidal irrigating solution capable of dissolving 
tissue [6, 7]; it also possesses also a bleaching effect [8] and it can be used in combination with EDTA, which is a chelator capable of removing smear layer from the root canal walls [9]. Another commonly used irrigating solution in endodontic treatment is chlorhexidine which also has a bactericidal effect [10]. It has been shown that chlorhexidine has a bactericidal effect against Enterococcus faecalis, [11] which is frequently found during endodontic re-treatment.

As early as 1917, Howe [12] reported that silver in form of an ammoniacal silver nitrate solution had a sterilizing effect on infected coronal as well as root dentin. Different research groups have investigated the bactericidal effect of silver diamine fluoride in dentistry and reported that it has a bactericidal effect against bacteria found in root canal infections such as Streptococcus mutans, Actinomyces naeslundii and Enterococcus faecalis [13-15]. The silver-diamine based product Riva Star is a two-component system: silver diamine fluoride and potassium iodide. However, it has been, so far, clinically employed as a desensitizer of sensitive dentin [16]. Thus, the aim of this study was to investigate in vitro the bactericidal properties of silver diamine fluoride and potassium iodide, alone and in combination in different concentrations against three bacteria commonly found in root canal samples: two facultatively anaerobic strains, coccal $(E$. faecalis) or rod-shaped (A. naeslundii) and an obligately anaerobic one (P. micra). Actinomyces naeslundii can be found in carious dentin and in root caries $[17,18]$ thus also in root canal systems [19]. Parvimonas micra is more frequently isolated from periodontal pockets [20]; yet, it can also be found in root canal systems [21]. Enterococcus faecalis occurs in gastrointestinal tracts of humans and other mammals [22]. According to Gold et al. [23] it gains access to the oral cavity through food ingestion and is often isolated from infected endodontically treated teeth $[11,24]$.

\section{Methods}

Riva Star (SDI Limited, Bayswater, Australia) is a twophase (38\% silver diamine fluoride [SDF] and potassium iodide [PI]) tooth desensitizing and cavity cleanser system. The potential bactericidal effect of SDF and PI, as well as a combination of the two solutions (SDF + PI) was tested using three bacterial strains belonging to species commonly found in endodontic infections. Two strains were obtained lyophilized from the German Collection of Microorganisms and Cell Cultures GmbH (DSMZ, Braunschweig, Germany), the facultatively anaerobic Enterococcus faecalis DSM 20376 and the obligately anaerobic Parvimonas micra DSM 20468. The third strain, also facultatively anaerobic, Actinomyces naeslundii A65 was obtained from the Centre for Hygiene and
Medical Microbiology, Bonn, Germany. E. faecalis 20376 and $A$. naeslundii $\mathrm{A} 65$ were grown as liquid cultures in Schaedler bouillon (BBL Schaedler Broth, Becton Dickinson and Company, Sparks, MD, USA) or on Schaedler agar plates. P. micra 20468 was grown in Anaerobe Basal Broth (Oxoid Ltd., Basingstoke, Hampshire, UK) and on agar plates prepared from the broth. Anaerobic conditions were obtained through incubation of the bacterial cultures in an anaerobic jar containing a GasPak envelope producing $\mathrm{H}_{2}$ and $\mathrm{CO}_{2}$ (GasPak EZ; Becton Dickinson and Company, Sparks, MD, USA) for $24 \mathrm{~h}$ (E. faecalis 20376), 48 h (A. naeslundii A65) or 72 h (P. micra 20468), at $37{ }^{\circ} \mathrm{C}$ (Heratherm Incubator, Thermo Scientific, Langenselbold, Germany). An inoculum of $40 \mu \mathrm{l}$ was used for the liquid cultures. Purity of the bacterial cultures was confirmed each time by taking a sample, placing it on a microscope slide and visually analyzing it using a phase contrast microscope (Carl Zeiss, Jena, Germany; 1250x).

A modified agar diffusion technique was used to obtain preliminary information about a potential antibacterial effect of the liquids from Riva Star. $100 \mu \mathrm{l}$ of the bacterial cultures were applied to the respective agar plates with a spreader, using a turntable. Then sterile paper discs (Oxoid Ltd, Basingstoke, Hampshire, UK) were placed on top of the agar, and $10 \mu \mathrm{l}$ of the liquids were applied to the paper discs. The antibacterial effect of SDF alone was tested undiluted, and to simulate possible residual fluids in the root canal system, diluted to $19 \%$, to $9.5 \%$ and to $3.8 \%(100 \% \mathrm{SDF}=38 \% ; 50 \%=19 \% ; 25 \%=9.5 \%$; $10 \%=3.8 \%$ ) with sterile saline; PI was tested only undiluted. For the combined effect, $5 \mu \mathrm{l}$ of SDF (undiluted, diluted to $19 \%$, to $9.5 \%$ and to $3.8 \%$ ) and $5 \mu \mathrm{l}$ of the undiluted PI were applied together to the sterile paper discs. After incubation for 24-72 h, depending on the bacterial strain as described above, the diameters of the inhibition zones were measured and expressed in centimeters.

In an effort to simulate clinical conditions that would allow applying the solutions directly to the bacteria with the micro brushes provided with the Riva Star system, an in vitro model was developed. Individual bacterial colonies of similar size were obtained by streaking an inoculation loop with the respective bacteria on the corresponding agar plates, using the quadrant streak technique. The plates were then incubated as described above, depending on the bacteria, for 24 , 48 or $72 \mathrm{~h}$ at $37^{\circ} \mathrm{C}$. For each bacterial strain four colonies of the same size were needed for each experiment, one as untreated control, one in contact with SDF, one with PI and one with SDF + PI. To determine the viable count of the controls, a colony was picked and placed into a sterile Eppendorf tube containing $1 \mathrm{ml}$ of sterile saline and mixed on a vortex (Janke \& Kunkel IKALabortechnik, Staufen, Germany). Serial dilutions of 
$10^{-1}$ dilution steps were performed until dilutions of up to $10^{-6}$ were reached. $100 \mu \mathrm{l}$ of each dilution were then plated on the respective agars and incubated as described above. The number of colony-forming units (CFUs) on plates containing 30-300 colonies was then counted and converted to the number of organisms per milliliter. The remaining three colonies were placed on sterile paper discs, and undiluted SDF, PI or SDF + PI was applied with the silver or green micro brushes provided with the Riva Star system. When the combined solutions were used, SDF was applied first and then PI. After $30 \mathrm{~s}$ of exposure time which is recommended by the manufacturer, each paper disc was placed into an Eppendorf tube with $1 \mathrm{ml}$ sterile saline and processed as described above for the controls. The numbers of colony forming units (CFUs) was counted on plates containing 300 or fewer colonies and converted to the number of organisms per milliliter.

The number of viable bacteria (CFUs) for the untreated controls was considered as $100 \%$ survival or $0 \%$ reduction rate. The numbers of CFUs of the treated bacteria were then compared with the controls, and reduction rates in percent were calculated for each strain and each exposure to SDF, PI and SDF + PI. The study design is depicted in Fig. 1.

\section{Statistical evaluation}

A statistical evaluation of the sizes of the inhibition zones (mean, median, standard deviation, minima, maxima and percentile) was carried out (SPSS Version 22 for Windows; Chicago, IL, USA) in cooperation with the Institute for Medical Biometry, Epidemiology and Informatics (IMBEI, University Medical Center of the Johannes Gutenberg-University, Mainz, Germany). The effect of the undiluted solutions of the SDF, PI and SDF + PI groups were compared for each bacterial strain by means of the nonparametric test for independent samples using the Kruskal-Wallis test $(p<0.05)$. The means, standard deviations and medians were determined for the colony-forming units (Excel 2013; Microsoft, Seattle PO, USA). The numbers of surviving bacteria are presented as scatterplots. For comparison of the number of viable bacteria and those after treatment with SDF, PI and PDF + PI the nonparametric Wilcoxon test for related samples was used $(p<0.05)$.

\section{Results}

In order to obtain preliminary information about a potential antibacterial effect of the liquids from Riva Star, a modified agar diffusion technique was used (Table 1). The largest inhibition zones were produced by undiluted silver diamine fluoride (SDF) ranging from $1.2 \pm 0.1 \mathrm{~cm}$

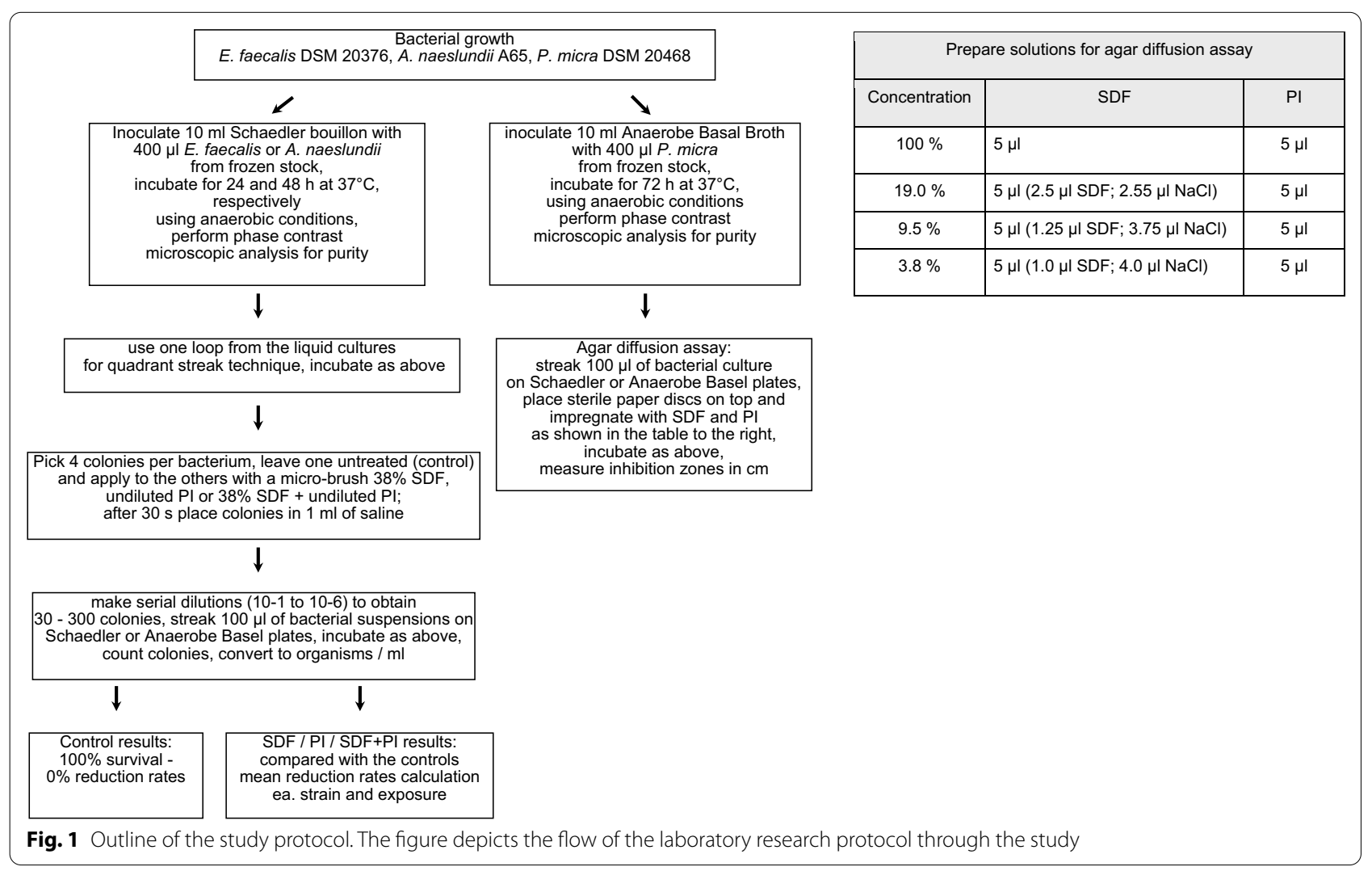


Table 1 Mean values and standard deviations (SD; \pm ) of the inhibition zones in centimeters of the three investigated strains: E. faecalis 20376, A. naeslundii A65 and P. micra 20468 in different concentrations of the solutions

\begin{tabular}{|c|c|c|c|c|c|c|}
\hline Solution/concentration & E. faecalis & $\mathrm{SD}\{ \pm)$ & A. naes/undii & $\mathrm{SD}\{ \pm)$ & P. micra & $\mathrm{SD}\{ \pm)$ \\
\hline SDF/38\% & 1.23 & 0.10 & 1.68 & 0.11 & 7.52 & 0.89 \\
\hline SDF/19\% & 0.88 & 0.08 & 1.42 & 0.13 & 5.48 & 0.23 \\
\hline SDF/9.5\% & 0.73 & 0.09 & 1.09 & 0.05 & 4.57 & 0.28 \\
\hline $\mathrm{SDF} / 3.8 \%$ & N/A & $\mathrm{N} / \mathrm{A}$ & 0.95 & 0.15 & 3.48 & 0.31 \\
\hline Pl/undiluted & 0.0 & 0.0 & 0.0 & 0.0 & 0.90 & 0.45 \\
\hline SDF/38\% + PI/undiluted & 0.95 & 0.11 & 1.29 & 0.15 & 5.49 & 0.28 \\
\hline SDF/19\% + PI/undiluted & 0.84 & 0.12 & 1.46 & 0.17 & 4.34 & 0.30 \\
\hline SDF/9.5\% + PI/undiluted & 0.93 & 0.17 & 1.50 & 0.09 & 3.55 & 0.18 \\
\hline SDF/3.8\%+PI/undiluted & $\mathrm{N} / \mathrm{A}$ & N/A & 1.50 & 0.10 & 3.25 & 0.18 \\
\hline
\end{tabular}

The differences in size were statistically significant for all three bacterial strains $(p<0.05)$. Riva Star is delivered with a 38\% SDF concentration $S D F$ silver diamine fluoride, $P /$ potassium iodide, $S D$ standard deviation, $M$ median, Max maxima, Min minima; $\mathrm{n}=6$

(E. faecalis 20376) to $7.5 \pm 0.9 \mathrm{~cm}$ (P. micra 20468), followed by undiluted SDF + PI ranging from $0.9 \pm 0.1 \mathrm{~cm}$ (E. faecalis 20376) to $5.4 \pm 0.3 \mathrm{~cm}$ (P. micra 20468). PI only produced inhibition zones in P. micra 20468 $(0.9 \pm 0.45 \mathrm{~cm})$. The differences in size were statistically significant for all three bacterial strains $(p<0.05)$.

After direct contact of the investigated bacterial species with the respective bactericidal solution, the numbers of viable bacteria were determined on plates containing
300 or fewer colonies as colony forming units (CFU) and are listed in Table 2 together with the numbers for the untreated controls, which are shown as scatterplot (Fig. 2). The calculated bactericidal rates in percent for each strain are also listed in Table 2.

After contact of $E$. faecalis with SDF, only a relatively low number of viable bacteria could be determined; yet, in only one trial a complete bactericidal effect of SDF was observed (Table 2). For A. naeslundii treated with SDF,

Table 2 CFUs of the control (untreated culture), after being in contact with the respective solutions (SDF, PI and SF + PI) and reduction rates in percent achieved by the respective antibacterial solutions

\begin{tabular}{|c|c|c|c|c|c|c|c|}
\hline Trial & Control & SDF & SDF (\%) & $\mathrm{PI}$ & $\mathrm{PI}(\%)$ & $\mathrm{SDF}+\mathrm{PI}$ & $\mathrm{SF}+\mathrm{PI}(\%)$ \\
\hline \multicolumn{8}{|c|}{ Enterococcus faecalis DSM 20376} \\
\hline Mean & $168.0 \times 10^{5}$ & $10.0 \times 10^{2}$ & 99.99 & $210.8 \times 10^{2}$ & 99.86 & $40.9 \times 10^{2}$ & 99.96 \\
\hline SD & 98.62 & 16.47 & 0.01 & 238.52 & 0.18 & 36.25 & 0.04 \\
\hline M & $141.5 \times 10^{5}$ & $1.75 \times 10^{2}$ & 99.99 & $98.5 \times 10^{2}$ & 99.93 & $35.3 \times 10^{2}$ & 99.98 \\
\hline Min & $83.0 \times 10^{5}$ & 0.0 & 99.97 & $29 \times 10^{2}$ & 99.51 & $1.6 \times 10^{2}$ & 99.89 \\
\hline Max & $353.0 \times 10^{5}$ & $41.5 \times 10^{2}$ & 99.99 & $604 \times 10^{2}$ & 99.98 & $84.8 \times 10^{2}$ & 99.99 \\
\hline \multicolumn{8}{|c|}{ Parvimonas micra DSM 20468} \\
\hline Mean & $32.2 \times 10^{5}$ & 0.0 & 100.00 & $37.9 \times 10^{2}$ & 99.98 & 0.0 & 100.00 \\
\hline SD & 22.06 & 0.0 & 0.00 & 68.78 & 0.03 & 0.0 & 0.00 \\
\hline$M$ & $26.4 \times 10^{5}$ & 0.0 & 100.00 & $2.8 \times 10^{2}$ & 99.99 & 0.0 & 100.00 \\
\hline Min & $5.2 \times 10^{5}$ & 0.0 & 100.00 & 0.0 & 99.93 & 0.0 & 100.00 \\
\hline Max & $66.0 \times 10^{5}$ & 0.0 & 100.00 & $173.0 \times 10^{2}$ & 100.00 & 0.0 & 100.00 \\
\hline \multicolumn{8}{|c|}{ Actinomyces naeslundii A65 } \\
\hline Mean & $150.0 \times 10^{5}$ & 0.0 & 100.00 & $443.3 \times 10^{2}$ & 99.73 & $4.8 \times 10^{2}$ & 100.00 \\
\hline SD & 67.18 & 0.0 & 0.0 & 472.55 & 0.25 & 8.13 & 0.01 \\
\hline M & $138.0 \times 10^{5}$ & 0.0 & 100.00 & $274.5 \times 10^{2}$ & 99.78 & 0.0 & 100.00 \\
\hline Min & $71.0 \times 10^{6}$ & 0.0 & 100.00 & $50.0 \times 10^{2}$ & 99.27 & 0.0 & 99.98 \\
\hline Max & $269.0 \times 10^{6}$ & 0.0 & 100.00 & $1250.0 \times 10^{2}$ & 99.95 & $19.5 \times 10^{2}$ & 100.00 \\
\hline
\end{tabular}

The calculated bactericidal rate for A. naeslundii and P. micra with SDF was $100 \%$ (no CFUs could be observed in any trial). The bactericidal rate of PI as well as of SDF + PI showed relatively high bactericidal rates in this group; yet, not as effective as SDF. Riva Star is delivered with a $38 \%$ SDF concentration

$S D F$ silver diamine fluoride, $P I$ potassium iodide, $S D$ standard deviation, $M$ median, Max maxima, Min minima; $\mathrm{n}=6$ 


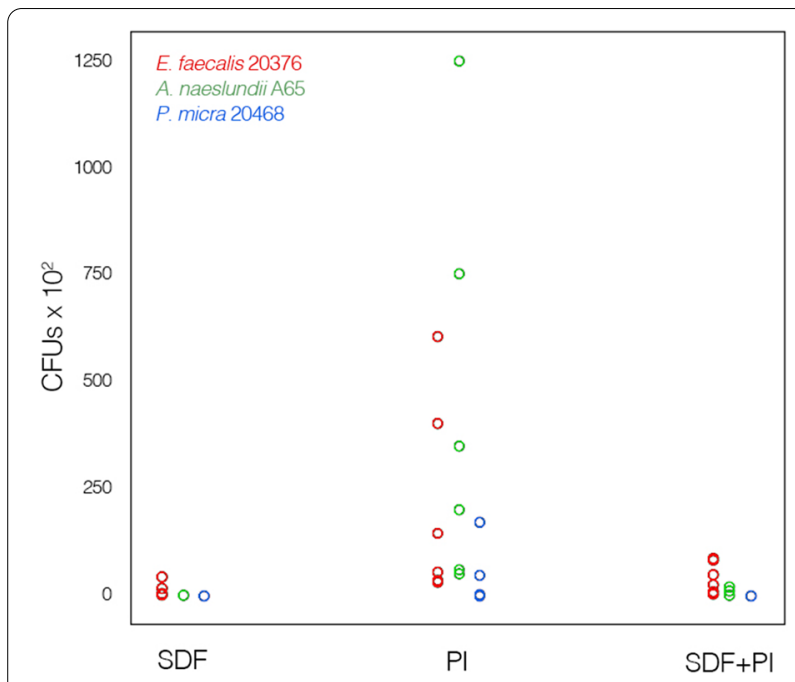

Fig. 2 Scatter diagram of the colony-forming units with E. faecalis 20376, A. naeslundii A65 and P. micra 20468 after contact with SDF, PI or SDF + PI. Both in E. faecalis and in A. naeslundii the highest variation in the number of CFUs is seen after treatment with $\mathrm{Pl}$, and lowest for treatment with SDF. In P. micra after contact with SDF or SDF + PI no colonies were detected, and only a low variation in the number of CFUs can be observed after treatment with PI (SDF silver diamine fluoride, $P$ / potassium iodide; $\mathrm{n}=6$ )

no viable cells could be detected. In four of the six trials after contact with SDF + PI no colonies could be found (Table 2). No viable cells were observed after contact of $P$. micra with SDF and SDF + PI (Table 2).

The difference in numbers of viable untreated bacteria and those after treatment with SDF, PI and PDF + PI was statistically significant for E. faecalis, A. naeslundii and $P$. micra $(p<0.05)$.

\section{Discussion}

To the best of our knowledge, Riva Star has been investigated and clinically used for caries arrest and as a desensitizer for hypersensitive teeth. In order to be able to use SDF and/or PI as a root canal disinfecting solution, their bactericidal efficacy was investigated in the present study on bacterial species that are frequently found in infected in root canals. An in vitro methodology was developed as an approach to investigate the bactericidal effect of SDF and PI, under standardized research parameters, in an effort to avoid bias in the results obtained. The bactericidal efficacy of SDF and PI could not be assessed in this study by means of a test tube dilution test because silver, from the SDF solution, forms an insoluble precipitate with components of the liquid culture media. A suitable method for this type of research could be the agar diffusion test. This technique has been used to investigate the bactericidal effect of sodium hypochlorite and chlorhexidine against the same bacterial species (E. faecalis,
A. naeslundii and P. micra) [25-27]. In order to test the ability of SDF to arrest the progression of carious lesions, the bactericidal effect of SDF at concentrations of $12 \%$ or $30 \%$ has been also been investigated with method, using S. mutans as test strain [28]; thus, it has been shown that this technique is a suitable one. However, in the agar diffusion test the contact time of the test solutions with the bacteria is at least $24 \mathrm{~h}$, which is by far longer than in a clinical situation during an endodontic treatment. Therefore, a method based on the preliminary results from the agar diffusion tests, namely the sizes of the inhibition zones, was developed to investigate the bactericidal effect of the Riva Star components, simulating the clinical applicability. The possibility to apply the Riva Star components by means of an endodontic standardized syringe was not taken into consideration in this study. However, it would be advisable to consider the possibility that, in a clinical situation, the irrigating syringe opening and/or needle could clog with the solution. SDF, PI and SDF + PI were applied to bacterial colonies on paper discs with help of the provided micro brushes, and after exposure for $30 \mathrm{~s}$ the bacterial suspensions were serially diluted and spread on agar plates. The viable bacteria count was determined after at least $24 \mathrm{~h}$ of incubation (depending on the bacterial species). Such a method has, to the best of our knowledge, has not yet been described in the literature. However, Vinson et al. [29] brought also bacteria (S. mutans) in direct contact for $60 \mathrm{~s}$ with $38 \%$ SDF, PI and SDF + PI, after which a reduction in the viable count was also observed.

Different in vitro studies report about the bactericidal efficacy of commonly endodontically employed root canal irrigation solutions, such as sodium hypochlorite and chlorhexidine against E. faecalis [30, 31], A. naeslundii $[26,32]$ and $P$. micra $[25,31]$; therefore, the bactericidal efficacy of SDF, PI and SDF + PI were also investigated using these three bacterial species. To the best of our knowledge, few reports have been published concerning the bactericidal effect of $3.8 \%$ SDF [13, 14] and PI [33] as endodontic disinfecting solutions. An effective bactericidal effect of $3.8 \%$ SDF against $E$. faecalis in root dentin $[13,14]$ and $3.8 \%$ SDF against $A$. naeslundii as part of a cariogenic biofilm [15, 34] has been reported. A $56 \%$ bactericidal rate of the Silver Star product SDF + PI has been reported for S. mutans in human dentin samples [35]. Hiraishi et al. [13], with a different research methodology, reported an effective bactericidal effect of 3.8\% SDF after 15 min exposure of E. faecalis in biofilms formed on nitrocellulose filters. Silver nanoparticles within an alcoholic solution proved also to have a bactericidal effect against $E$. faecalis, on bovine dentin specimens after 1 week of exposure [36]. On the contrary, Spratt et al. [31] report that colloidal 
silver was ineffective against biofilms produced from isolates of E. faecalis and P. micra from infected root canal dentin. Although the bactericidal rates of SDF, PI and SDF + PI obtained in this investigation against $E$. faecalis, A. naeslundii and P. micra ranges from 99.27 to $100 \%$ and could also be considered as relatively high values as well as the ones reported in most studies previously mentioned [13-15, 28, 33, 34], a comparison or discussion with the aforementioned studies and ours is difficult due to the different research methodologies and parameters employed, such as exposure times of $30 \mathrm{~s}$ up to several days, employed. The results from the study by Vinson et al. [29], where the direct contact of the bacteria with the agents employed led to the highest reduction in viable counts by $38 \%$ SDF, followed by SDF + PI (both higher than 99.9\%) and then PI (97\%), resemble the ones obtain in this study, even though they studied a different bacterium (S. mutans).

Furthermore, no report has been published whether SDF has the ability to dissolve tissue or to remove the smear layer; thus, in our opinion for the time being, SDF and/or PI could only be recommended as enhancing disinfectant solutions (e.g. as last disinfecting procedure prior to root canal filling) and therefore, a comparison of the results obtained in this investigation with SDF, SDF + PI and PI and commonly employed root canal irrigating solutions is difficult, not only due to the different research methodologies employed, but also due to their different clinical aims. SDF showed an advantageous bactericidal effect of on E. faecalis, A. naeslundii and $P$. micra. However, a potential clinical implication of SDF in the root canal system could be a possible precipitation of silver, thus, its clinical endodontic employment should be carefully considered. It has been reported that 3.8\% SDF has the ability to penetrate into the dentin tubules up to $40 \mu \mathrm{m}$ [13] and to occlude tubular orifices even after removal of the smear layer. The authors are of the opinion that the presence of silver deposits in dentinal tubules suggest that SDF can reduce/eliminate biofilms formed in the dentinal tubules and to prevent reinfection by the relatively insoluble silver salts [13]. However, the root canal space should be thoroughly obturated with sealers and filing materials to prevent apical and coronal leakage [37]. Therefore, the employment of SDF as an irrigating solution should be carefully considered since precipitated silver could occlude areas of the complex root canal system morphology [38], such as the dentin tubules, thus, acting as a barrier to an optimum penetration of the root canal filling materials into them. This fact can be considered as a potential sealing quality hindrance for the root canal filling sealers and or thermoplastic applied guttapercha, thus, could influence the outcome of an endodontic treatment. A further SDF endodontic employment limitation is the silver precipitation tooth discoloration potential $[39,40]$. This negative side effect could be avoided through a meticulously employment of the substance. Yet, even if the bacteria in the root canal would be completely eliminated after a final irrigation with SDF, a latent discoloration potential of such tooth would conduce to a clinical aesthetic unacceptable situation, for both patient and operator. Moreover, on one hand it has been reported that SDF was cytotoxic to gingival fibroblasts in concentrations as low as $0.01 \%$ [41] and on the other hand, clinically oriented researches $[42,43]$ have reported mild temporary gingival reactions, such as erythema, bleeding, white changes, ulceration and pigmentation $24 \mathrm{~h}$ after the application of SDF. Thus, a potential accidentally caused irritating effect of SDF into the periapical tissues, especially during incomplete root formation cases, should be carefully considered when the irrigation protocol decision is taken.

\section{Conclusions}

Silver diamine fluoride has a bactericidal effect on $E$. faecalis, $A$. naeslundii and P. micra.

The combination of silver diamine fluoride with potassium iodine and potassium iodine itself had a relatively lower bactericidal effect in the investigated bacterial strains in comparison with silver diamine fluoride.

\section{Abbreviations}

CFU: Colony forming units; DSMZ: German Collection of Microorganisms and Cell Cultures GmbH; EDTA: Ethylene diamine tetraacetic acid; PI: Potassium iodide; SDF: Silver diamine fluoride.

\section{Acknowledgements}

The authors are very grateful to Dr. Kathy Saranpa for her valuable support.

\section{Authors' contributions}

B.B.M., A.C. and T.G.W. conceived and designed the experiments. A.C. and Y.I. performed the experiments. B.B.M., A.C., T.G.W., and C.T. analyzed the data. B.B.M., A.C., T.G.W. wrote the manuscript with input from all the other authors. All authors read and approved the final manuscript.

\section{Funding}

Not applicable.

Availability of data and materials

The datasets generated and/or analyzed during the current study are available from the corresponding author on reasonable request.

\section{Declarations}

Ethics approval and consent to participate

All procedures were in accordance with the ethical standards of the local research committee and with the 1964 Helsinki declaration and its later amendments or comparable ethical standards. In accordance to the local Ethical Committee, further formal approval of this kind of study was not necessary.

Consent for publication

Not applicable. 


\section{Competing interests}

The authors declare that they have no competing interests.

\section{Author details}

${ }^{1}$ Department of Restorative, Preventive and Pediatric Dentistry, School of Dental Medicine, University of Bern, Freiburgstrasse 7, 3010 Bern, Switzerland. ${ }^{2}$ Department of Periodontology and Operative Dentistry, University Medical Center of the Johannes Gutenberg-University, Mainz, Germany.

Received: 18 May 2020 Accepted: 22 March 2021

Published online: 07 April 2021

\section{References}

1. Seltzer S, Bender IB, Ziontz M. The interrelationship of pulp and periodontal disease. Oral Surg Oral Med Oral Pathol. 1963;16:1474-90.

2. Andreasen FM, Kahler B. Pulpal response after acute dental injury in the permanent dentition: clinical implications - a review. J Endod. 2015:41:299-308.

3. Dahlén G. Microbiology and treatment of dental abscesses and periodontal_endodontic lesions. Periodontol. 2000;2002(28):206-39.

4. Grossman LI. Root canal therapy. 2nd ed. Philadelphia: Lea and Febiger; 1946.

5. Dutner J, Mines P, Anderson A. Irrigation trends among American Association of Endodontists members: a web-based survey. J Endod. 2012;38:37-40.

6. Svec TA, Harrison JW. Chemomechanical removal of pulpal and dentinal debris with sodium hypochlorite and hydrogen peroxide vs normal saline solution. J Endod. 1977;3:49-53.

7. Austin JH, Taylor HD. Behavior of hypochlorite and of chloramine-t solutions in contact with necrotic and normal tissues in vivo. J Exp Med. 1918:27:627-33.

8. Dakin HD. The antiseptic action of hypochlorites: the ancient history of the "New Antiseptic."Br Med J. 1915;2:809-10.

9. Ostby N. Chelation in root canal therapy. Ethylenediamine tetraacetic acid for cleansing and widening of root canals. Odontol Tidskr. 1957;6:142-9.

10. Stabholz A, Kettering J, Aprecio R, Zimmerman G, Baker PJ, Wikesjö UM. Antimicrobial properties of human dentin impregnated with tetracycline $\mathrm{HCl}$ or chlorhexidine. An in vitro study. J Clin Periodontol. 1993;20:557-62.

11. Sundqvist G, Figdor D, Persson S, Sjögren U. Microbiologic analysis of teeth with failed endodontic treatment and the outcome of conservative retreatment. Oral Surg Oral Med Oral Pathol Oral Radiol Endod. 1998;85:86-93.

12. Howe PR. A method of sterilizing and at the same time impregnating with a metal, affected dentinal tissue. Dent Cosmos. 1917;59:891-904.

13. Hiraishi N, Yiu CKY, King NM, Tagami J, Tay FR. Antimicrobial efficacy of 3.8\% silver diamine fluoride and its effect on root dentin. J Endod. 2010;36:1026-9.

14. Mathew VB, Madhusudhana K, Sivakumar N, Venugopal T, Reddy RK. Antimicrobial efficiency of silver diamine fluoride as an endodontic medicament-an ex vivo study. Contemp Clin Dent. 2012;3:262-4.

15. Mei ML, Li QL, Chu CH, Lo EM, Samaranayake LP. Antibacterial effects of silver diamine fluoride on multi—species cariogenic biofilm on caries. Ann Clin Microbiol Antimicrob. 2013;12:1-7.

16. Craig GG, Knight GM, Mclntyre JM. Clinical evaluation of diamine silver fluoride/potassium iodide as a dentine desensitizing agent. A pilot study. Aust Dent J. 2012:57:308-11.

17. Brailsford SR, Lynch E, Beighton D. The isolation of Actinomyces naes/undii from sound root surfaces and root carious lesions. Caries Res. 1998:32:100-6.

18. Fure S, Romaniec M, Emilson CG, Krasse B. Proportions of Streptococcus mutans, lactobacilli and Actinomyces spp in root surface plaque. Scand J Dent Res. 1987:95:119-23.

19. Debelian GJ, Olsen I, Tronstad L. Bacteremia in conjunction with endodontic therapy. Endod Dent Traumatol. 1995;11:142-9.

20. Kremer BH, Loos BG, van der Velden U, van Winkelhoff AJ, Craandijk J, Bulthuis HM, et al. Peptostreptococcus micros smooth and rough genotypes in periodontitis and gingivitis. J Periodontol. 2000;71:209-18.

21. Wittgow WC, Sabiston CB. Microorganisms from pulpal chambers of intact teeth with necrotic pulps. J Endod. 1975;1:168-71.

22. Gilmore MS, Clewell DB, Ike Y, Shankar N. Enterococci. From commensals to leading causes of drug resistant infection. Boston: Massachusetts Eye and
Ear Infirmary; 2014. https://www.ncbi.nlm.nih.gov/books/NBK190424/pdf/ Bookshelf_NBK190424.pdf.

23. Gold OG, Jordan HV, van Houte J. The prevalence of enterococci in the human mouth and their pathogenicity in animal models. Arch Oral Biol. 1975;20:473-7.

24. Pinheiro ET, Gomes BPFA, Ferraz CCR, Sousa ELR, Teixeira FB, Souza-Filho FJ. Microorganisms from canals of root-filled teeth with periapical lesions. Int Endod J. 2003;36:1-11

25. Carson KR, Goodell GG, McClanahan SB. Comparison of the antimicrobial activity of six irrigants on primary endodontic pathogens. J Endod. 2005:31:471-3.

26. Radcliffe CE, Potouridou L, Qureshi R, Habahbeh N, Qualtrough A, Worthington $\mathrm{H}$, et al. Antimicrobial activity of varying concentrations of sodium hypochlorite on the endodontic microorganisms Actinomyces israelii, A. naeslundii, Candida albicans and Enterococcus faecalis. Int Endod J. 2004;37:438-46.

27. Siqueira JF, Batista MM, Fraga RC, de Uzeda M. Antibacterial effects of endodontic irrigants on black-pigmented gram-negative anaerobes and facultative bacteria. J Endod. 1998;24:414-6

28. de Almeida LFD, Cavalcanti YW, Valença AMG. In vitro antibacterial activity of silver diamine fluoride in different concentrations. Acta Odontol Latinoam. 2011;24:127-31.

29. Vinson LA, Gilbert PR, Sanders BJ, Moser E, Gregory RL. Silver diamine fluoride and potassium iodide disruption of in vitro Streptococcus mutans biofilm. J Dent Child (Chic). 2018;85:120-4.

30. Chávez de Paz LE, Davies JR, Bergenholtz G, Svensäter G. Strains of Enterococcus faecalis differ in their ability to coexist in biofilms with other root canal bacteria. Int Endod J. 2015:48:916-25.

31. Spratt DA, Pratten J, Wilson M, Gulabivala K. An in vitro evaluation of the antimicrobial efficacy of irrigants on biofilms of root canal isolates. Int Endod J. 2001:34:300-7.

32. Chávez de Paz L, Sedgley CM, Kishen A, editors. The root canal biofilm. Heidelberg: Springer; 2015

33. Pallotta RC, Ribeiro MS, de Lima Machado ME. Determination of the minimum inhibitory concentration of four medicaments used as intracanal medication. Aust Endod J. 2007:33:107-11.

34. Chu CH, Mei L, Seneviratne CJ, Lo ECM. Effects of silver diamine fluoride on dentine carious lesions induced by Streptococcus mutans and Actinomyces naes/undii biofilms. Int J Paediatr Dent. 2012;22:2-10

35. Hamama HH, Yiu CK, Burrow MF. Effect of silver diamine fluoride and potassium iodide on residual bacteria in dentinal tubules. Aust Dent J. 2015:60:80-7.

36. Bednarski M, Soska-Czop A, Zarzycka B, Ebert J, Pawlicka H. Nanocare plus SilverGold ${ }^{\circledR}$ can eliminate Enterococcus faecalis from dentinal tubules. Dent Med Probl. 2013;50:418-23.

37. Schilder $\mathrm{H}$. Filling root canals in three dimensions. Dent Clin N Am. 1967:11:723-44.

38. Briseño Marroquín B, Paqué F, Maier K, Willershausen B, WolfTG. Root canal morphology and configuration of 179 maxillary first molars by means of micro - computed tomography: an ex vivo study. J Endod. 2015:41:2008-13.

39. Chu CH, Lo ECM, Lin HC. Effectiveness of silver diamine fluoride and sodium fluoride varnish in arresting dentin caries in Chinese pre-school children. J Dent Res. 2002;81:767-70.

40. Zhao IS, Mei ML, Burrow MF, Lo ECM, Chu CH. Effect of silver diamine fluoride and potassium iodide treatment on secondary caries prevention and tooth discolouration in cervical glass ionomer cement restoration. Int J Mol Sci. 2017:18:340.

41. Fancher ME, Fournier S, Townsend J, Lallier TE. Cytotoxic effects of silver diamine fluoride. Am J Dent. 2019:32:152-6.

42. Vasquez E, Zegarra G, Chirinos E, Castillo JL, Taves DR, Watson GE, et al. Short term serum pharmacokinetics of diammine silver fluoride after oral application. BMC Oral Health. 2012;12:60.

43. Castillo JL, Rivera S, Aparicio T, Lazo R, Aw TC, Mancl LL, et al. The shortterm effects of diammine silver fluoride on tooth sensitivity: a randomized controlled trial. J Dent Res. 2011:90:203-8.

\section{Publisher's Note}

Springer Nature remains neutral with regard to jurisdictional claims in published maps and institutional affiliations. 